\title{
A Comparative Study on Effect of Low Dose Ketamine versus Dexamethasone on Intraoperative Nausea and Vomiting during Cesarean Section under Spinal Anesthesia
}

\author{
Sona Emami* \\ Specialist in Anesthesiology and intensive care, Ardabil University of medical sciences, Iran
}

*Corresponding author: Sona Emami. Specialist in Anesthesiology and intensive care, Ardabil University of Medical Sciences, Iran; Email: sona_emami@yahoo.com

Received: February 02, 2021; Accepted: February 08, 2021; Published: March 25, 2021

\begin{abstract}
Background and objectives: Intra Operative Nausea and Vomiting (IONV), is distressing for patients, obstetricians, anesthetists; and may increase the risk of visceral injury during surgery by involuntary uncontrolled abdominal movements. In this study, we aimed to compare the antiemetic efficacy of low dose Ketamine versus Dexamethasone to decrease the incidence of IONV during Cesarean Section (C/S) under spinal anesthesia.

Materials and methods: This study was performed on 135 full term parturient women, aged between 18 and 40 years; candidate for cesarean section under spinal anesthesia at operation room. The parturient were allocated randomly to three groups using randomized blocking method. Group $\mathrm{I}(\mathrm{n}=$ 45) received $8 \mathrm{mg}$ Dexamethasone with total syringe volume of $5 \mathrm{ml}$, while group II $(\mathrm{n}=45)$ received $20 \mathrm{mg}$ Ketamine with total syringe volume of 5 $\mathrm{ml}$, and control group III $(\mathrm{n}=45)$ received $5 \mathrm{ml}$ normal saline. During the intraoperative period, the number of nausea, retching and vomiting episodes were recorded by an anesthetist who was blinded to the drug administered to the patient. Intraoperative hypotension and Bradycardia were recorded. The patient was also requested to report the symptoms of nausea, vomiting and shivering that may occur at the intervals. Vomiting was managed by Metoclopramide $10 \mathrm{mg}$ slowly IV. A standardized surgical technique was used in all cesarean sections. Finally the statistical analysis was done using Statistical Package for Social Science version 21 program (SPSS21).

Results: This study, performed on 135 parturient women divided into three groups with 45 members in each one (first group received Dexamethasone, second and third groups were Ketamine and Placebo receivers in respect). Average age was $30.35 \pm 5.94$ years in Dexamethasone group, $29.97 \pm 6.18$ years in Ketamine group, and $29.6 \pm 6.03$ in control group $(\mathrm{P}=0.840)$. In this study there was statistically insignificant increase in the rate of successful prevention of IONV $(\mathrm{P}=0.062)$ and shivering $(\mathrm{P}=0.550)$ using preoperative Ketamine and Dexamethasone. But there was statistically significant decrease in the rate of IONV in Ketamine group when compared to Dexamethasone group. The studied groups were comparable as regard to mean arterial blood pressure and heart rate, there was no statistically significant difference between groups during the study period. Also intraoperatively, there was no statistically significant difference in hypotensive episodes $(P=0.885)$, total Ephedrine administered (the average amount in those who suffered hypotension and received Ephedrine $(P=0.623)$, and bradycardia $(P=0.146)$ between the studied groups. There was statistically significant decrease in the incidence of bradycardia in Ketamine group when compared to Dexamethasone group.
\end{abstract}

Conclusion: This study showed that there was no statistically significant decrease difference between groups receiving Dexamethasone and low dose Ketamine compared to control group during the operation period regarding the decrease rate of nausea and vomiting, hypotension and shivering.

\section{Introduction}

Minor side effects such as nausea and vomiting have been seen in more than $66 \%$ of cases [1-3]. Sudden contractions of Diaphragm during labor, which is unpleasant for patients can occur due to manipulation and abdominal traction. IONV (Intra Operative Nausea and Vomiting) is distressing for patients, obstetricians, anesthetists; and may increase the risk of visceral injury during surgery by involuntary uncontrolled abdominal movements [4-6]. Many factors may contribute to this high rate of IONV on the patients undergoing abdominal surgery under regional anesthesia: psychological changes due to anxiety, sympathetic block and the resultant hypotension secondary to spinal anesthesia, probably are the most important factors. Hypotension can induce the emetic symptoms by leading to cerebral hypo perfusion [7-9]. In addition, the chance of nausea and vomiting during labor is supposedly increased due to hormonal changes and increased internal pressure of uterus [10]. Considering the Causes of nausea and vomiting and its side effects; improvement of these conditions can have a significant effect on maternal treatment at the time of cesarean section. Prevention of hypotension or prescription of some kind of effective drugs is therefore important for the prevention of IONV. Dexamethasone, Ondansetron, ketamine, Pethidine and tramadol are some of the several drugs which are being used for prevention and treatment of the mentioned unwanted event 
[4,11-18]. Numerous studies have shown the effect of Dexamethasone in reducing nausea and vomiting $[2,4,11]$. It is assumed that Ketamine induced rising of blood pressure can reduce the incidence of spinal induced hypotension and consequently reduce nausea and vomiting $[7,17,19]$. In this study, we aimed to compare the efficacy of low dose ketamine versus Dexamethasone on IONV during C/S under spinal anesthesia.

\section{Patients and Methods}

This study is a type of randomized controlled, prospective, double blind clinical trial. The statistical population of the present study were patients referred to Alevi Educational and Medical Center of Ardabil city of Iran, with an indication for cesarean section during the year 2018. This study was performed on 135 ASA I-II female patients, between 18 and 40 years of age undergoing a planned C/S under spinal anesthesia and included three groups: Dexamethasone group, ketamine group and Placebo group, which were the recipients of sole normal saline. Sample volume is based on volume calculation sample for RCT studies with significance level of $0.05 \%$ and power of $80 \%$; considering $60 \%=\mathrm{P} 1$ in Placebo group and $28 \%=\mathrm{P} 2$ in Dexamethasone group, 38 patients were counted for each group. In the same way, the sample volume is based on the volume calculation sample for RCT studies with significance level of 0.05 and power of $80 \%$; and in terms of $\mathrm{P} 1=60 \%$ in placebo group and P3 $=22 \%$ In the low dose ketamine group, 27 people for each group was calculated. And in terms of $20 \%$ possible loss, 7 people were added to Dexamethasone group and 18 patients were added to low dose ketamine group; thus 45 patients were enrolled in the present study to receive each drug for prevention of intraoperative nausea and vomiting.

After obtaining approval from the clinical research ethics committee of medical university with the code: IR.arums.rec.1396.230 and IRCT number: 20150808023559 N18, all participants provided a written informed consent. 135 Patients were randomly divided into three groups using simple sampling method and block method (AABBCC) as follow: Ketamine group (including 45 patients receiving $20 \mathrm{mg}$ Ketamine with total syringe volume of $5 \mathrm{ml}$ ), Dexamethasone group (including 45 patients receiving $8 \mathrm{mg}$ Dexamethasone with total syringe volume of $5 \mathrm{ml}$ ) and control group (including 45 patients who received $5 \mathrm{ml}$ of normal saline). All 3 syringes were similar in terms of color (content of all 3 syringes were colorless) and volume (all 3 syringes contained $5 \mathrm{ml}$ of liquid substance). All three drugs were separately in syringes with specific codes of A,B,C on them. The three syringes were given by the second anesthetist to the anesthetist who was unaware of the content of the syringe and would administer it in a double-blind fashion before surgical incision and after spinal anesthesia. We excluded patients with, preeclampsia, eclampsia, psychiatric disorder, gastrointestinal disease, drug allergies, infection, diabetes, glaucoma, epileptic patients, and those on antiemetic agent in the last $24 \mathrm{hs}$. All parturient received $1000 \mathrm{ml}$ Ringer solution IV over 30 min through 18 or 20 G IV lines before spinal anesthesia. Patients evaluated with standard monitoring including electrocardiogram, noninvasive arterial blood pressure measurement and pulse oximetry. Spinal anesthesia performed using a 25-gauge spinal needle in sitting position, through the L3-4, or L4-5 interspace. $2.5 \mathrm{ml}$ of $0.5 \%$ heavy
Marcaine (Marcaine Spinal Heavy Ampule 0.5\%, Astrazeneca) was administered to the subarachnoid space. Parturient were moved to supine position with operation bed turned 20 degree left lateral tilt to decrease the Aortocaval compression caused by the uterus and reducing hypotension after spinal anesthesia. The parturient were allocated randomly to three groups, ketamine group $(n=45)$ received $20 \mathrm{mg}$ Ketamine with total syringe volume of $5 \mathrm{ml}$, Dexamethasone group $(\mathrm{n}=45)$ received $8 \mathrm{mg}$ Dexamethasone diluted in $5 \mathrm{ml}$ normal saline and control group $(\mathrm{n}=45)$ received $5 \mathrm{ml}$ normal saline. the three syringes were given by the second anesthetist to the anesthetist who was unaware of the content of the syringe and would administer it in a double-blind fashion slowly IV over1 min before surgical incision. Face mask oxygenation used to all patients at a rate of $5 \mathrm{~L} / \mathrm{min}$, the level of sensory blockage was evaluated before the surgical incision. We excluded Patients with insufficient level of analgesia who were in need of general anesthesia. Estimated fluid deficits and maintenance requirements were replaced with Ringer's solution IV, Intraoperative hypotension (MABP less than $20 \%$ of the basal reading) was managed by increasing the infusion rate of Ringer solution with injecting increments of $10 \mathrm{mg}$ Ephedrine IV and if hypotension persisted another bolus Ephedrine was given. Bradycardia ( $\mathrm{HR}<50$ beat $/ \mathrm{min}$ ) managed by Atropine $(0.5 \mathrm{mg})$. After delivery of the baby, routine use of 10 units Oxytocin IV plus 20 units slow infusion if necessary were given to all parturient to enhance uterine contraction. We recorded the incidence of hypotension and increments of Ephedrine. During the intraoperative period, nausea, retching and vomiting episodes were recorded by an anesthetist who was blinded to the type of drug administered to the patient, questioning the patient in frequent intervals about the emetic symptoms. The patient was also requested to report any symptoms that may occur. Vomiting was managed by Metoclopramide $10 \mathrm{mg}$ slowly IV, and IV analgesic (Fentanyl 50 microgram) was injected and the amount was recorded if required after delivery of the baby. A standardized surgical technique was used in all cesarean sections by Pfannenstiel incision. Nausea and Vomiting, evaluated through the following scoring table: Score 1: No nausea and vomiting, score 2: Only nausea, score 3: one to two episodes of nausea and vomiting, score4: Nausea and vomiting more than twice. Patients' shivering score was evaluated according to the following shivering table: score0: No shivering observed, score 1 : goose pumps and bristling, score 2: shivering localized to the group of body muscles, score 3: shivering in different bunches of body muscles score 4: shivering involves movements of the entire body.

The statistical analysis was done using SPSS program (statistical package for social science) version 21, Anova, Chi Square and Fisher Tests. All the tests were considered meaningful at the level of 0.05 . All information and the answers were confidential.

\section{Results}

This study performed on 135 parturient women divided into three groups with 45 members in each one (first group received Dexamethasone, second and third groups were Ketamine and Placebo receivers in respect). There was no statistically significant differences in age between the three groups $(P=0.840)$. In the analysis of educational background, it was observed that 29 patients 
in Dexamethasone group (64.4\%), 29 patients in ketamine group (64.4\%) and 26 patients in control group (57.8\%) were undergraduate. Anthropometric findings were observed and there was no significant difference in BMI among Dexamethasone, Ketamine and control groups $(\mathrm{P}=0.246)$. ASA evaluated in 6 levels and it was observed that the majority of the patients in three groups were at I-ASA level (P $=0.165)$. All pregnancies were full term. None of the patients in the three groups had history of previous cardiac disease. None of them had history of cigarette smoking. Anesthetic level was adequate in all patients and sensory block was at T4 level. There was statistically insignificant increase in the rate of successful prevention of IONV in Ketamine group when compared to Dexamethasone group ( $P$ $=0.062$ ). The studied groups were comparable as regard to systolic blood pressure, diastolic blood pressure, mean arterial blood pressure and heart rate, there was no statistically significant difference between groups at different spectrum of time during the study period (before surgical incision up to 75 minutes after operation). After analyzing the data in all three groups using Repeat measurement test regarding Systolic blood pressure there was significant difference between three groups. There were significant differences regarding diastolic blood pressure, mean arterial blood pressure and heart rate in each group during the different periods of time throughout the operation. The highest rate of bradycardia occurred in Dexamethasone group with 6 patients $(13.3 \%)(\mathrm{P}=0.146)$. After two-by-two analyzing of the data in the study groups, it was observed that the incidence of bradycardia in Ketamine group was significantly lower than Dexamethasone group ( $\mathrm{P}$ $=0.049)$. while there was no significant differences between Ketamine group compared with control group $(\mathrm{P}=0.091)$, and Dexamethasone group compared with control group $(\mathrm{P}=0.748)$.

Intraoperative hypotension was evaluated in three groups (MABP less than $20 \%$ of basic level) and the group with the most hypotensive cases was Dexamethasone group with 28 cases (62/2\%); there were 26 patients $(57 / 8 \%)$ in each of Ketamine and placebo groups. Analysis of results showed that this finding is not statistically significant.

Regarding shivering, it was observed that shivering occurred in 1 patient at Dexamethasone group with grade $1(2 / 2 \%)$ and 2patients in control group (1 patient in grade 1 and 1 patient in grade 2) (4/4\%) and none of the patients in Ketamine group had shivering in three groups statistically was insignificant $(\mathrm{P}=0.550)$.

The need for Ephedrine administration was analyzed and observed that in 32 patients of Dexamethasone group (71/1\%), 31 patients of ketamine group (68/9\%) and 32 patients of Control group (71/1\%) single dose of Ephedrine was administered which was statistically insignificant.

There were no significant differences between three groups regarding the amount of received Ephedrine.

The average amount of received Ephedrine in Dexamethasone group was calculated $6.13 \pm 16.22 \mathrm{mg}$, it was $18 \pm 12 / 17 \mathrm{mg}$ in ketamine group and 18/22 $\pm 48 / 12 \mathrm{mg}$ in Control group $(\mathrm{P}=0.623)$.

There was statistically significant increase in the rate of successful prevention of only nausea in Ketamine group when compared to Dexamethasone group $(\mathrm{P}=0 / 023)$. The incidence of IONV was statistically insignificant when compared Ketamine group versus control group $(\mathrm{P}=0 / 180)$ and Dexamethasone group versus control group $(\mathrm{P}=0 / 335)$.

Regarding shivering, it was observed that there was single case of shivering with grade $1(2 / 2 \%)$ and 2 patients with grade $4(4 / 4 \%)$ in Dexamethasone group, and 1 patient with grade 1 and 1 patient with grade 2 in control group whereas no patient with shivering had been recorded in Ketamine group. There were statistically insignificant differences among three groups considering shivering $(P=0 / 550)$.

\section{Discussion}

In this study, 135 patients were divided in to three groups with 45 members in each (First group was recipient of Dexamethasone, second group was recipients of low dose Ketamine and the third group was placebo).

In the study performed by Ahmed Hassanein and Eissa Mahmoud [19] in Egypt in 2014 on 135 patients candidate for cesarean section, Aiming to determine the effects of low dose Ketamine versus Dexamethasone on intraoperative nausea and vomiting during $\mathrm{C} / \mathrm{S}$; The incidence of nausea and vomiting in Dexamethasone group $(28 / 8 \%)$ and Ketamine group (22/2 \%) (51/1\%) were significantly lower than the control group.

But in the present study there was statistically insignificant difference in low dose ketamine group and dexamethasone group compared to the control group in terms of nausea and vomiting in the study performed by Kalani et al. [20] on 120 patients aiming the Effect of Ondansetron and Dexamethasone on nausea and Vomiting under Spinal Anesthesia, it was reported that in the 1 st and 5th minutes after surgery, the incidence of nausea and vomiting, was $0 \%$ in ondansetron group and 10/2\%, 13/3\% respectively in Dexamethasone group, and it was observed that incidence of nausea and vomiting in ondansetron group was significantly lower.

In another study by Shalu et al. [21] titled "the Efficacy of Intravenous Dexamethasone in Prolonging the Duration of Spinal Anesthesia in Elective Cesarean Section" performed on 60 patients; Patients were divided into two groups.

The first group received Dexamethasone and the second group received Normal saline. It was observed that there were no statistically significant differences between the two groups in terms of nausea and vomiting which was identical to the findings of the present study.

In the study performed by Behdad et al. [22] on "Effects of Intravenous Ketamine during Spinal Anesthesia" in 60 Pregnant Women Undergoing Cesarean Section in 2013, the first group received $30 \mathrm{mg}$ Ketamine with 1 mg Midazolam and the second group received Midazolam alone.

The statistical differences in nausea and vomiting in the first group Compared to the second group, was significantly high.

In the study performed by Modir et al. [23] under the title of "Prophylactic efficacy of Dexamethasone, Ketamine and Dexmedetomidine against intra- and postoperative nausea and vomiting under spinal anesthesia on 140 Pregnant woman undergoing cesarean section"; Patients were divided into 4 groups. 
First group received normal saline, 2nd group received Dexamethasone, the 3rd group received Ketamine and the 4th group received Dexmedetomidine.

It was observed that all three drugs regarding nausea and vomiting are significantly effective compared to the control group and the incidence of nausea and vomiting is significantly less in Dexmedetomidine group compared to others.

In the present study the incidence of hypotension was insignificant in different groups $(P=0 / 885)$ while in the study of Hassanein et al. [19] there was no difference in Ephedrine administration (the average amount in those who suffered hypotension and received ephedrine), between Ketamine and dexamethasone groups, while the control group showed a significant high dose of total Ephedrine administration when compared to Ketamine and Dexamethasone groups ( $8 \pm 3.2$ versus $4.5 \pm 2.1$ in Ketamine group, and $5.3 \pm 2$ in Dexamethasone group), and a significant high rate of hypotensive episodes when compared to ketamine group (84.4\% versus 64\%).

In the study of Shalu et al. [21] heart rate, systolic blood pressure, diastolic blood pressure and arterial oxygen saturation in the Dexamethasone group had no significant difference with the control group; Which is in line with the results of our study. In the study of Kalani et al. [20] there were no significant differences between groups in mentioned items.

In Behdad et al. [22] study it was observed that Ketamine failed to make any significant changes to patients' vital signs. In Modir et al. [23] the lowest heart rate (in normal range) and blood pressure was in Dexmedetomidine group and showed a significant difference compared to other three groups. But in our study, heart rate hadn't any significant difference between Ketamine group and Dexamethasone group. In the study of Solhpour et al. [24] with the title of "Comparison of prophylactic use of Meperidine, Meperidine plus Dexamethasone, and Ketamine plus Midazolam in preventing of shivering during spinal anesthesia" None of the four groups of this study showed any statistically significant difference in vital signs. Reviewing these studies, it was observed that Ketamine and Dexamethasone can't make any significant changes in vital signs in a single dose and the majority of studies showed that vital signs were relatively more stable with these two drugs compared to the control group. In current study there wasn't any significant difference regarding shivering among three groups. while in the study of Solhpour et al. [24] administration of combined Dexamethasone with Meperidine, could reduce the incidence of shivering. There was no significant differences among the four groups in nausea and vomiting. It also showed that Ketamin can reduce the incidence of nausea and vomiting while Dexamethasone can't. The current study is in line with this finding.

\section{Conclusion}

This study showed that nausea and vomiting and bradycardia significantly decreased in low dose Ketamine group compared to Dexamethasone group while there weren't any differences in hypotension and shivering between the two groups. There was no statistically significant difference between groups receiving
Dexamethasone and low dose Ketamine compared to control group during the operation period regarding the decrease rate of nausea and vomiting, hypotension and shivering.

\section{Acknowledgements}

This article is derived from my final $\mathrm{PhD}$ thesis Which has been submitted to research deputy of Ardabil University of Medical Science and translated by me for the Journal of Clinical Research and Medicine. I would like to express my gratitude to my parents and my sisters who gave me the needed emotional support to persevere through what seemed like a totally overwhelming and never ending task.

\section{References}

1. Balki M, Carvalho JC (2005) Intraoperative nausea and vomiting during cesarean section under regional anesthesia. Int J Obstet Anesth 14(3): 230-241. [crossref]

2. Rodseth RN, Gopalan PD, Cassimjee HM, Goga S (2010) Reduced incidence of postoperative nausea and vomiting in black South Africans and its utility for a modified risk scoring system. Anesth Analg 110(6): 1591-1594. [crossref]

3. Griffiths JD, Gyte GML, Paranjothy S, Brown HC, Broughton HK, et al. (2012) Interventions for preventing nausea and vomiting in women undergoing regional anaesthesia for caesarean section. Cochrane Database Syst Rev 9: CD007579. [crossref]

4. Voigt M, Fröhlich CW, Hüttel C (2013) Prophylaxis of intra- and postoperative nausea and vomiting in patients during cesarean section in spinal anesthesia. $\mathrm{Med} \mathrm{Sci}$ Monit 19: 993-1000. [crossref]

5. Ngan Kee WD, Khaw KS, Ng FF (2004) Comparison of phenylephrine infusion regimens for maintaining maternal blood pressure during spinal anesthesia for caesarean section. Br J Anaesth 92(4): 469-74. [crossref]

6. Cunningham FG, leveno KJ, Bloom SL (2010) Williams obstetrics and Gynecology 2010. 23th ed ed. USA: McGraw-Hill, pp: 544-77.

7. Miller RD, Cohen NH, Eriksson LI, Fleisher LA, WienerKronish JP, Young WL. Miller's Anesthesia.8th ed. USA. Churchill Livingstone. 2015.

8. Apfel CC, Roewer N (2003) Risk assessment of postoperative nausea and vomiting. Int Anesthesiol Clin 41: 13-32. [crossref]

9. Morgan EJ, Mikhail MS, Murray J (2006) Nonvolatile anesthetic agents, clinical anesthesiology. 4th ed., vol 1. Lange Medical Books/McGraw-Hill.

10. Rasooli S, Moslemi F, Khaki A (2014) Effect of subhypnotic doses of propofol and midazolam for nausea and vomiting during spinal anesthesia for cesarean section. Anesthesiol Pain Med 4(4): e19384. [crossref]

11. Kalani N, Zabetian H, Sanie MS, Deylami M, Radmehr M, et al. (2017) The Effect of Ondansetron and Dexamethasone on Nausea and Vomiting under Spinal Anesthesia. World Journal of Plastic Surgery 6(1): 88-93.

12. Pecora FST, Malbouisson LM, Torres MLA (2009) Supplemental oxygen and the incidence of perioperative nausea and vomiting in cesarean sections under subarachnoid block. Rev Bras Anestesiol 59: 558-569. [crossref]

13. Habib AS, Itchon-Ramos N, Phillips-Bute BG, Gan TJ (2006) Transcutaneous acupoint electrical stimulation with the Relief Band for the prevention of nausea and vomiting during and after cesarean delivery under spinal anesthesia. Anesth Analg 102: 581-584. [crossref]

14. Rowbotham DJ (2005) Recent advances in the nonpharmacological management of postoperative nausea and vomiting. Br J Anaesth 95: 77-81. [crossref]

15. Demirhan A, Tekelioglu YU, Akkaya A, Ozlu T, Yildiz I, et al. (2013) Antiemetic effects of dexamethasone and ondansetron combination during cesarean sections under spinal anesthesia. African Health Sciences 13(2): 475-482. [crossref]

16. Voigt M, Fröhlich CW, Hüttel C, Kranke P, Mennen J, et al. (2013) Prophylaxis of intra- and postoperative nausea and vomiting in patients during cesarean section in spinal anesthesia. Medical Science Monitor: International Medical Journal of Experimental and Clinical Research 19: 993-1000. [crossref] 
Sona Emami (2021) A Comparative Study on Effect of Low Dose Ketamine versus Dexamethasone on Intraoperative Nausea and Vomiting during Cesarean Section under Spinal Anesthesia

17. Rahmanian M, Leysi M, Hemmati AA, Mirmohammadkhani M (2015) The Effect of Low-Dose Intravenous Ketamine on Postoperative Pain Following Cesarean Section with Spinal Anesthesia: A Randomized Clinical Trial. Oman Medical Journal 30(1): 11-16. [crossref]

18. Behdad S, Hajiesmaeili MR, Abbasi HR, Ayatollahi V, Khadiv Z, et al. (2013) Analgesic Effects of Intravenous Ketamine during Spinal Anesthesia in Pregnant Women Undergone Caesarean Section; A Randomized Clinical Trial. Anesthesiology and Pain Medicine 3(2): 230-233. [crossref]

19. Hassanein A, Mahmoud E (2015) Effect of low dose ketamine versus dexamethasone on intraoperative nausea and vomiting during cesarean section under spinal anesthesia. Egyptian Journal of Anaesthesia 31: 59-63.

20. Kalani N, Zabetian H, Sanie MS, Deylami M, Radmehr M, et al. (2017) The Effect of Ondansetron and Dexamethasone on Nausea and Vomiting under Spinal Anesthesia. World J Plast Surg 6(1): 88-93. [crossref]
21. Shalu PS, Ghodki PS (2017) To Study the Efficacy of Intravenous Dexamethasone in Prolonging the Duration of Spinal Anesthesia in Elective Cesarean Section. Anesth Essays Res 11(2): 321-325. [crossref]

22. Behdad S, Hajiesmaeili MR, Abbasi HR, Ayatollahi V, Khadiv Z, et al. (2013) Analgesic Effects of Intravenous Ketamine during Spinal Anesthesia in Pregnant Women Undergone Caesarean Section; A Randomized Clinical Trial. Anesth Pain Med 3(2): 230-3. [crossref]

23. Modir H, Moshiri E, Kamali A, Shokrpour M, Shams N (2019) Prophylatic efficacy of dexamethasone, ketamine and dexmedetomidine against intra- and postoperative nausea and vomiting under spinal anesthesia. Formos J Surg 52: 17-23.

24. Solhpour A, Jafari A, Hashemi M, Hosseini B, Razavi S, et al. (2016) A comparison of prophylactic use of meperidine, meperidine plus dexamethasone, and ketamine plus midazolam for preventing of shivering during spinal anesthesia: a randomized, double-blind, placebo-controlled study. J Clin Anesth 34: 128-35. [crossref]

Emami S (2021) A Comparative Study on Effect of Low Dose Ketamine versus Dexamethasone on Intraoperative Nausea and Vomiting during Cesarean Section under Spinal Anesthesia. J Clin Res Med Volume 4(1): 1-5. 